\title{
A single-surgeon experience in reconstruction of femoro-acetabular offset and implant positioning in direct anterior approach and anterolateral MIS approach with a curved short stem
}

\author{
Matthias Luger ${ }^{1}$ (1) $\cdot$ Rainer Hochgatterer ${ }^{1} \cdot$ Matthias C. Klotz $^{1} \cdot$ Jakob Allerstorfer ${ }^{1} \cdot$ Tobias Gotterbarm $^{1}$ . \\ Bernhard Schauer ${ }^{1}$
}

Received: 17 October 2020 / Accepted: 26 May 2021 / Published online: 2 June 2021

(c) The Author(s) 2021

\begin{abstract}
Purpose Minimally invasive surgery using short stems in total hip arthroplasty gained more popularity. The differences in change of hip offset and implant positioning in minimally invasive approaches are not fully known. Therefore, this study was conducted to evaluate the difference in reconstruction of hip offset and implant positioning in direct anterior approach (DAA) and minimally invasive anterolateral approach (AL MIS).

Methods A single surgeon series of 117 hips (117 patients; mean age 65.54 years \pm 11.47 ; index surgery 2014-2018) were included and allocated into two groups: group A (DAA) with 70 hips and Group B (AL MIS) with 47 patients operated. In both groups the same type of cementless curved short hip stem and press fit cup was used.

Results Both groups showed an equal statistically significant increase of femoral $(p<0.001)$ and decrease of acetabular offset $(p<0.001)$. Between both groups no statistically significant difference in offset reconstruction, leg length difference or implant positioning could be found. Leg length increased in both groups significantly and leg length discrepancy showed no difference (group A: $-0.06 \mathrm{~mm}$; group B: $1.11 \mathrm{~mm} ; p<0.001$ ). A comparable number of cups were positioned outside the target zone regarding cup anteversion.

Conclusion The usage of a curved short stem shows an equal reconstruction of femoro-acetabular offset, leg length and implant positioning in both MIS approaches. The results of this study show comparable results to the existing literature regarding change of offset and restoration of leg length. Malposition of the acetabular component regarding anteversion poses a risk.
\end{abstract}

Keywords Total hip arthroplasty $\cdot$ short stem $\cdot$ Minimally invasive $\cdot$ direct anterior approach $\cdot$ Anterolateral approach · Offset reconstruction

Matthias Luger

Matthias.luger@kepleruniklinikum.at

Rainer Hochgatterer

Rainer.hochgatterer@kepleruniklinikum.at

Matthias C. Klotz

Matthias.klotz@kepleruniklinikum.at

Jakob Allerstorfer

jakob.allerstorfer@keplernuniklikum.at

Tobias Gotterbarm

Tobias.gotterbarm@kepleruniklinikum.at

Bernhard Schauer

Bernhard.schauer@kepleruniklinikum.at

1 Department of Orthopaedics and Traumatology, Kepler University Hospital Linz, Krankenhausstrasse 9, 4020 Linz, Austria

\section{Introduction}

In recent years minimally, invasive approaches gained more popularity [1, 2]. Minimally invasive approaches in total hip arthroplasty (THA) include the direct anterior (DAA), the anterolateral and the posterior approach to the hip [1]. Minimally invasive approaches (MIS) show the advantage of less blood loss [3], less perioperative pain and rapid recovery [4-6]. However, MIS approaches show the disadvantage of less surgical exposure posing the risk of potential implant malpositioning [7-9]. Femoral short stems are used more frequently in minimally invasive THA partly because of facilitating soft-tissue sparing implantation [10]. The development of short stems aimed at various issues, such as bone 
preservation of the proximal femur, the reduction of stress shielding and mid-thigh pain incidence [10-12].

Commonly used straight stems show excellent long-time outcomes [13], but have the disadvantage of limited ability to restore the femoral offset (FO) due to their straight stem design [14]. With modern femoral short stems, the correct restoration of natural hip anatomy should be facilitated [14, 15]. Besides leg length (LL), FO influences the postoperative outcome, dislocation rate, wear and revision rate [14]. FO is part of the abductor moment arm [14]. Restoration of the native FO increases range of motion, abductor muscle function and decreases polyethylene wear [14, 16-20]. Several studies even suggest a beneficial effect of an increased FO on abductor muscle force and joint reaction [21-23]. Given these findings, reconstruction of hip offset (HO) and LL shows a high clinical relevance. Recent studies suggest a sufficient reconstruction with new short stem systems [15] with better control of reconstructing FO compared to straight stem systems [24]. The possibility of correct offset reconstruction depends on the offset options of short stem systems [15]. Certain short stem systems with limited offset options show a significant loss of $\mathrm{HO}$ and increased valgus position [25].

Besides implant specific aspects the impact of the chosen approach on offset reconstruction is limited in the current literature. Studies show a potentially superior HO reconstruction and LL restoration in DAA compared to posterior and lateral approaches [26, 27]. The offset reconstruction of short stem systems in anterolateral approach also shows a good potential for correct reconstruction of offset and hip anatomy in THA $[15,24]$.

The data on reconstruction of $\mathrm{HO}$ and differences in offset reconstruction between different minimally invasive approaches is limited in current literature. In addition, minimally invasive approaches may have the risk of implant malpositioning. Therefore, this study was conducted to compare the difference of reconstruction of femoro-acetabular offset, leg length and implant positioning with a curved short stem in direct anterior approach and minimally invasive anterolateral approach.

\section{Materials and methods}

\section{Study cohort}

In this retrospective study a single-surgeon experience in reconstruction of femoro-acetabular offset and implant positioning in MIS THA using a DAA or AL MIS approach was analysed. 153 hips in 136 patients with index surgery between 2014 and 2018 were eligible. 35 hips were excluded. 15 patients were operated on both sides. In these cases, the first implantation was included because of statistical reasons.
4 bilateral one-stage implantations have been excluded, 5 hips because of peri- or postoperative complications and 3 hips because of missing landmarks on postoperative X-ray. 9 patients were lost to follow up. Therefore 117 hips in 117 patients were included in this study. Dependent on the surgical approach, patients were assigned either to group A (direct anterior approach) or group B (minimally invasive supine anterolateral approach). Group A consisted of 70 hips and group B of 47 hips. The study was approved by the institutional review board (EK-No.: 1239/2019). All procedures performed in studies involving human participants were in accordance with the ethical standards of the institutional and/or national research committee and with the $1964 \mathrm{Hel}-$ sinki declaration and its later amendments or comparable ethical standards.

\section{Surgical procedure and implants}

The procedures were performed by a single fellowship trained surgeon. DAA was carried out in a supine position on a standard operating table as previously described [28, 29]. Minimally invasive anterolateral approach also was carried on a standard operating table in supine position [30]. Flouroscopy was neither used for DAA nor anterolateral approach. The standardized peri- and postoperative protocol was identical in both groups, including single-shot antibiotics (Cefuroxime $1.5 \mathrm{~g}$ i.v. perioperatively), weight-bearing as tolerated, Indometacin $75 \mathrm{mg}$ daily for the prevention of heterotopic ossification for 4 days and $40 \mathrm{mg}$ low-molecular weight heparin or Rivaroxaban $10 \mathrm{mg}$ for 28 days postoperatively as prophylaxis for deep vein thrombosis.

A cementless, curved short stem was used in all patients (Fitmore ${ }^{\circledR}$ stem, ZimmerBiomet, Warsaw, IN, USA). The titanium alloy stem (Ti Al6V4) has a porolock Ti-VPS coating in the proximal part to enhance bone ingrowth and is available in four different neck angle options $\left(127^{\circ}, 129^{\circ}\right.$, $137^{\circ}, 140^{\circ}$ ) [31]. A cementless titanium press-fit cup with or without screws (Allofit ${ }^{\circledR} /$-S, ZimmerBiomet, Warsaw, IN, USA) was used in all patients. In both groups the aim was a secure press-fit fixation, restoration of an equal leg length, reconstruction of the preoperative hip offset, cup inclination between 30 and $50^{\circ}$ and cup anteversion between 10 and $30^{\circ}[8,32]$. Preoperative planning of the prosthesis size and position was performed on anterior-posterior radiographic pelvis templates in all cases.

\section{Radiographic evaluation}

Radiographic measurements were performed on pre and 3 month postoperative low centered anteroposterior (AP) radiographs of the pelvis. Radiographic measurement was performed on digital low-centered AP radiographs of the pelvis [33]. Radiographs were taken with the patient in 
standing position and with both legs in $15^{\circ}$ internal rotation and the central beam was directed on the symphysis pubis [7]. To achieve an accurate measurement of the hip anatomy a double coordinate system was applied on both the preoperative and the postoperative images [15, 34]. Radiographic analysis was done using MediCAD ${ }^{\circledR}$ Software V5.1 (HECTEC GmbH, Altdorf, Germany). The hip center of rotation (COR) was defined using a circle tool determining the diameter of the femoral head and its center [35]. The femoral offset (FO) was determined as the perpendicular distance between the COR and the proximal femoral shaft axis (FSA) [33, 35]. Acetabular offset (AO) was measured as the perpendicular distance between the COR and line $\mathrm{T}$, with $\mathrm{T}$ being the perpendicular line on the transteardrop line (TT) through the ipsilateral teardrop figure [33]. Hip offset (HO) was calculated as the sum of FO and AO [33]. Stem alignment was measured as the difference in degrees between anatomic femoral shaft and vertical stem axis [36]. Cup inclination was defined as the angle between the TT line and the line connecting the most superior and inferior aspect of the cup. Cup anteversion was measured and calculated according to the formula by Lewinnek et al. [32], as recently validated by computer tomography based data [37]. Radiographic leg length (LL) was measured as the perpendicular distance between line TT and the middle of the lesser trochanter [7]. To characterize the anatomical shape of the proximal femur and the thickness of cortical bone, the cortical index (CI) according to Dorr et al. [38] were determined. A high $\mathrm{CI}$ indicates a thick cortical bone [38]. The canal fill index (CFI) was determined to evaluate the metaphyseal/diaphyseal filling of the femoral canal by the cementless stem implant on 3 different heights (CFI I: at the level of the LT, CFI II: $1 \mathrm{~cm}$ below the LT, CFI III: $3 \mathrm{~cm}$ below the LT). On each height, the horizontal diameter of the stem implant was measured and divided by the endosteal medullary canal diameter, multiplied by 100 [39, 40]. On preoperative X-ray FO, AO, HO and LL were measured. On postoperative $\mathrm{X}$-ray $\mathrm{FO}, \mathrm{AO}, \mathrm{HO}, \mathrm{LL}$, cup inclination, cup anteversion, stem alignment, CI, CFI, CFII and CFIII were measured. Pre- and postoperative measurements are shown in Figs. 1 and 2.

\section{Statistical analysis}

Statistical analysis was calculated with SPSS version 26 (IBM SPSS statistics, Chicago, IL, USA). Descriptive analysis was done for the parameters age, sex, offset and implant positioning. After exploratory data analysis, a Kolmogorov-Smirnov test was performed. As not all variables met the criteria for a normal distribution, non-parametric test was used. A Mann-Whitney $U$ test was performed for testing between pre- and postoperative variables as well as between group A (DAA) and group B (AL MIS). The level of significance was $p<0.05$.

\section{Results}

A total of 117 hips in 117 patients have been included in this study. Gender showed a nearly equal distribution with 61 female and 56 male patients. The indication for THA was primary coxarthrosis in 105 patients, avascular necrosis in 7 patients and secondary arthrosis due to mild hip dysplasia (Crowe 1) in 5 patients. 70 hips (group A) were implanted
Fig. 1 Preoperative X-ray with measurement of femoral offset (FO), acetabular offset (AO), leg length difference (LL) and Cortical Index (CI)

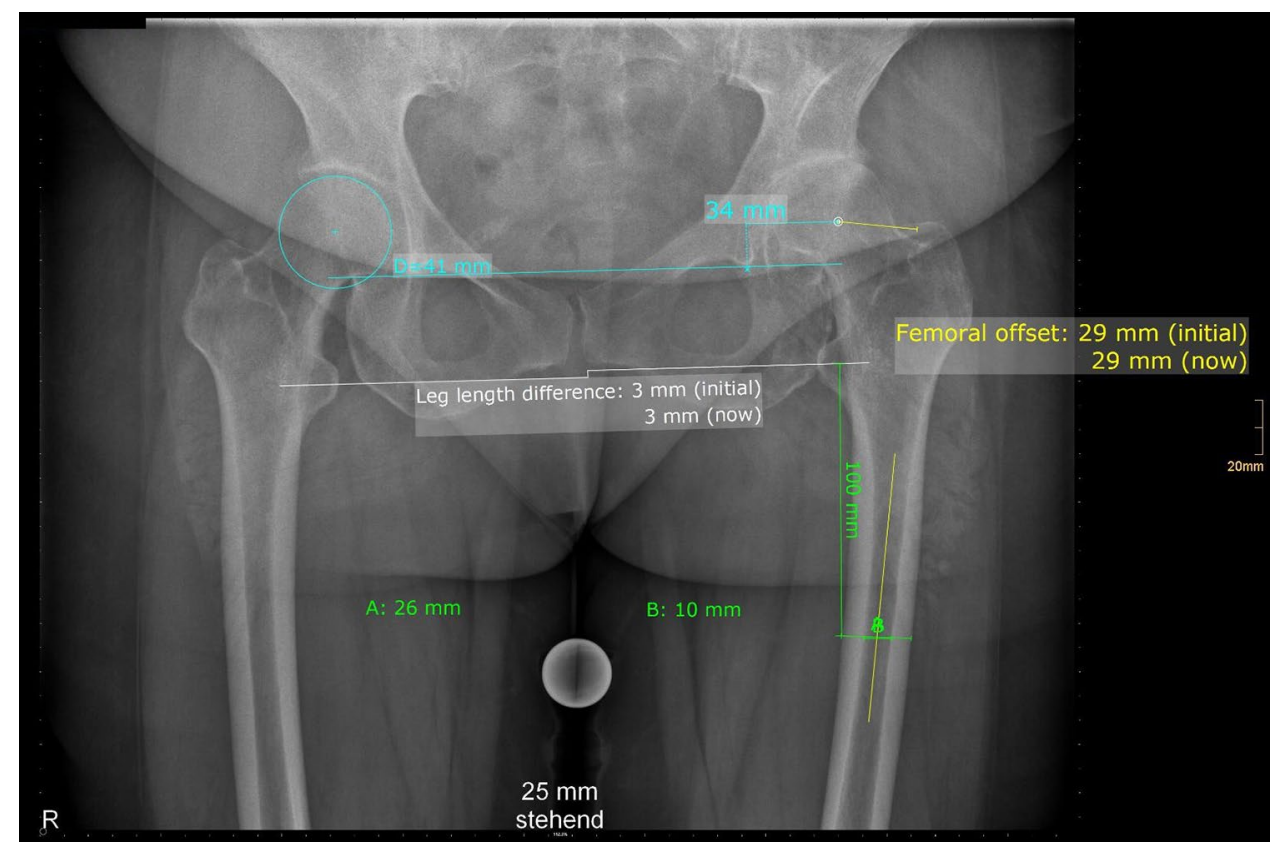


Fig. 2 Postoperative X-ray with measurement with femoral offset $(\mathrm{FO})$, acetabular offset (AO), leg length difference (LL), stem alignment, cup inclination and anteversion, Canal Fill Indices (CFI) I, II and III

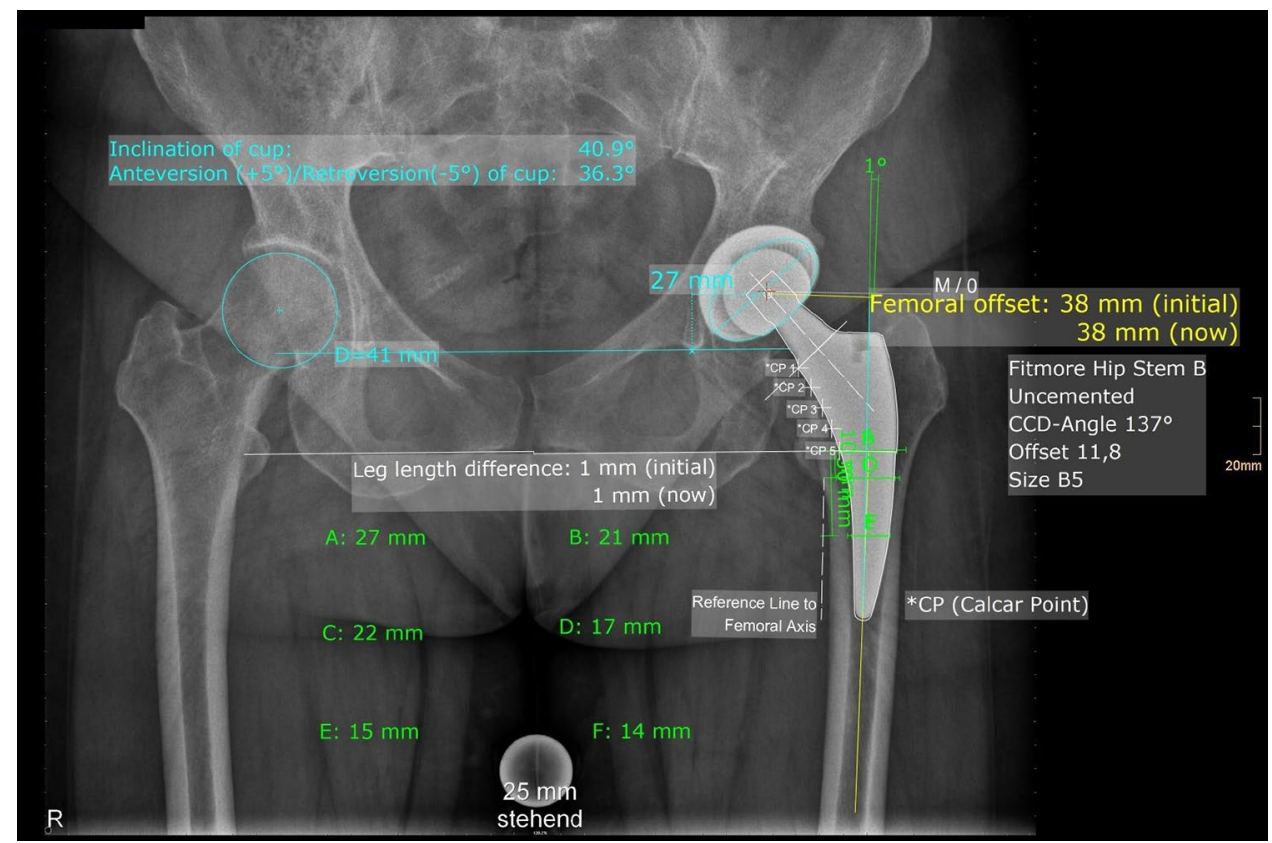

through DAA and 47 hips (group B) were implanted through a minimally invasive anterolateral approach. Average age at operation in the general study cohort was 65.54 years (Min 30.79; Max 87.25; SD11.47). Average age at operation in group A was 65.86 years (Min 38.08; Max 86.91; SD 11.65) and in group B 65.05 years (Min 30.79; Max 87.25; SD 11.31).

\section{Offset reconstruction}

FO increased in both groups significantly $(p<0.001)$ and AO decreased in both groups $(p<0.001)$. HO increased in both groups but only showed a statistical significance change for group A. The difference in pre- and postoperative FO, $\mathrm{AO}$ and $\mathrm{HO}$ showed no statistically significant difference in testing group A vs group B. LL also changed in both groups significantly $(p<0.001)$ and the LL difference showed no statistically significant difference in testing both groups. The detailed results for offset and leg length analysis are shown in Table 1.

\section{Implant positioning}

Implant positioning showed in both groups similar results for inclination and anteversion. The acetabular components showed an inclination within the defined target zone in $92.9 \%$ of cases for group A and $83 \%$ for group B. A statistically significant difference for cups without the target zone could not be found between both groups. Testing for cups outside the target zone regarding anteversion also showed no statistically significant difference. Both groups showed a similar number of cups outside the target zone regarding
Table 1 Results of offset analysis and leg length difference (all parameters in $\mathrm{mm}$ )

\begin{tabular}{|c|c|c|c|c|}
\hline \multirow{2}{*}{$\begin{array}{l}\text { Vari- } \\
\text { able }\end{array}$} & \multicolumn{2}{|c|}{ Group A (DAA) } & \multicolumn{2}{|c|}{ Group B (AL MIS) } \\
\hline & Preop & Postop & Preop & Postop \\
\hline FO & $40.83 \pm 7.37$ & $49.70 \pm 8.45$ & $42.38 \pm 7.99$ & $50.85 \pm 8.66$ \\
\hline$p$ value & $<0.001$ & & $<0.001$ & \\
\hline $\begin{array}{l}\text { FO dif- } \\
\text { fer- } \\
\text { ence }\end{array}$ & $8.87 \pm 5.94$ & & $8.47 \pm 4.71$ & \\
\hline$p$ value & 0.96 & & & \\
\hline $\mathrm{AO}$ & $34.34 \pm 4.56$ & $29.47 \pm 3.69$ & $34.68 \pm 4.41$ & $29.15 \pm 4.31$ \\
\hline$p$ value & $<0.001$ & & $<0.001$ & \\
\hline $\begin{array}{l}\text { AO dif- } \\
\text { fer- } \\
\text { ence }\end{array}$ & $-4.87 \pm 3.83$ & & $-5.53 \pm 4.33$ & \\
\hline$p$ value & 0.577 & & & \\
\hline $\mathrm{HO}$ & $75.17 \pm 9.42$ & $79.17 \pm 10.3$ & $77.06 \pm 9.81$ & $80 \pm 10.07$ \\
\hline$p$ value & 0.018 & & 0.165 & \\
\hline $\begin{array}{l}\text { HO } \\
\text { dif- } \\
\text { fer- } \\
\text { ence }\end{array}$ & $4 \pm 4.98$ & & $2.94 \pm 4.41$ & \\
\hline$p$ value & 0.435 & & & \\
\hline LL & $-3.57 \pm 5.49$ & $-0.06 \pm 4.49$ & $-3.66 \pm 6.02$ & $1.11 \pm 5.13$ \\
\hline$p$ value & $<0.001$ & & $<0.001$ & \\
\hline $\begin{array}{l}\text { LL dif- } \\
\text { fer- } \\
\text { ence }\end{array}$ & $3.51 \pm 5.42$ & & $4.77 \pm 4.66$ & \\
\hline$p$ value & 0.179 & & & \\
\hline
\end{tabular}

anteversion with $42.9 \%$ of cups in group A and $46.8 \%$ of cups in group B. Stem alignment showed an average varus 
angle of $5.33^{\circ}$ in group $\mathrm{A}$ and $5.46^{\circ}$ in group B without any statistical significance. In addition, the evaluation of canal filling index showed no statistically significant difference for CI, CFI, CFII and CFIII between both groups. Detailed results of implant positioning are shown in Table 2.

\section{Discussion}

Short stems were introduced partly because of theoretical advantage of better offset reconstruction [15]. A better reconstruction of femoro-acetabular offset and the natural anatomy of the hip is associated with better clinical and functional outcome [21-23]. The results show no statistically significant difference in comparing both minimally invasive approaches. Both approaches result in similar reconstruction of femoro-acetabular offset and leg length. HO increases in both groups but only shows a significant increase in DAA. However, the difference in increase in $\mathrm{HO}$ is $4 \mathrm{~mm}$ in DAA and 2.94 for AL MIS. The smaller group size in Group B (AL MIS) could be a factor of a missing statistical significance of pre- and postoperative HO. Furthermore, in testing between $\mathrm{HO}$ difference in DAA vs $\mathrm{AL}$ MIS no significant difference could be found.

Kutzner et al. [15] showed a statistically significant increase of $\mathrm{FO}$ and $\mathrm{HO}$ as well as a statistically significant decrease of AO in 109 patients in THA with a femoral neck preserving short stem (Optimys ${ }^{\circledR}$ Mathys Ltd, Bettlach, Switzerland) in minimally invasive supine anterolateral

Table 2 Results of implant positioning

\begin{tabular}{lll}
\hline Variable & Group A $(n=70)$ & Group B $(n=47)$ \\
\hline Cup inclination $\left(^{\circ}\right)$ & $40.63 \pm 5.95$ & $43.84 \pm 6.25$ \\
Within target zone & $65(92.9 \%)$ & $39(83 \%)$ \\
Outside target zone & $5(7.1 \%)$ & $8(17 \%)$ \\
$p$ value & 0.097 & \\
Cup anteversion $\left(^{\circ}\right)$ & $28.62 \pm 4.59$ & $30.82 \pm 6.08$ \\
Within target zone & $40(57.1 \%)$ & $25(53.2 \%)$ \\
Outside target zone & $30(42.9 \%)$ & $22(46.8 \%)$ \\
$p$ value & 0.675 & \\
Stem alignment $\left(^{\circ}\right)$ & $5.33 \pm 3.54$ & $5.46 \pm 3.44$ \\
$\quad($ varus/valgus) & & \\
$p$ value & 0.833 & $59.70 \pm 4.56$ \\
CI $(\%)$ & $59.72 \pm 5.62$ & \\
$p$ value & 0.761 & $80.25 \pm 8.29$ \\
CFI $(\%)$ & $79.8 \pm 7.26$ & $83.07 \pm 7.9$ \\
$p$ value & 0.717 & $83.81 \pm 10.72$ \\
CFII $(\%)$ & $82.7 \pm 7.6$ & \\
$p$ value & 0.703 & \\
CFIII $(\%)$ & $85.85 \pm 10.17$ & \\
$p$ value & 0.427 & \\
\hline
\end{tabular}

approach. The average increase of FO was $5.8 \mathrm{~mm}$ and $2.1 \mathrm{~mm}$ for HO . An average reduction of $3.7 \mathrm{~mm}$ was found in AO. Similar findings have been published by Erivan et al. [24] for the same short stem system. Erivan et al. [24] found a statistically significant increase of $4.7 \mathrm{~mm}$ in FO in 100 patients with THA with the same short stem system in anterolateral approach compared to $7.2 \mathrm{~mm}$ in straight stem arthroplasty in a matched control group with 100 patients. Compared to a straight system a statistically significant difference in increasing FO could be found with $p=0.0152$ [24]. Therefore, the short stem system was considered to provide better control in restoration of femoral offset [24]. Similar to these findings FO increased in THA with the femoral neck sacrificing curved short stem $\left(\right.$ Fitmore ${ }^{\circledR}$, ZimmerBiomet) in this study. While offset reconstruction in femoral neck sparing short stems is controlled by defining the correct femoral neck osteotomy, Fitmore short stem provides offset reconstruction by 4 different offset options. With this short stem system an increase of FO with $8.87 \mathrm{~mm}$ could be found in DAA and $8.47 \mathrm{~mm}$ in AL MIS approach. The findings of this study show a slightly higher increase in FO in both minimally invasive approaches compared to similar studies [15, 24]. A reason for higher increase in FO may be a result of a higher decrease of $\mathrm{AO}$ and medialization of the acetabular component. AO decreased with $4.87 \mathrm{~mm}$ in DAA and $5.53 \mathrm{~mm}$ in AL MIS compared to $3.7 \mathrm{~mm}$ in a comparable study [15]. A decrease of AO is typical in cementless press-fit acetabular cups. The medialization of the center of rotation is therefore compensated in increasing FO to achieve a stable hip joint and to prevent limitation in functional outcome because of a decreased HO. This is supported by the findings for both groups in this study. The results for increase of $\mathrm{HO}$ are comparable for both groups with $4 \mathrm{~mm}$ for DAA and $2.94 \mathrm{~mm}$ for AL MIS compared to $2.1 \mathrm{~mm}$ in a comparable study [15].

Leg length and leg length difference is also an important factor for a good clinical outcome and patient satisfaction. This study showed a statistically significant $(P<0.001)$ increase of LL in both groups with an average postoperative LL discrepancy of $-0.06 \mathrm{~mm}$ for DAA and $1.11 \mathrm{~mm}$ in AL MIS. These findings show a comparable restoration of LL for both approaches with Fitmore short stem. The findings are also comparable to findings in other studies with an increase of LL of $2.4 \mathrm{~mm}$ and $2.86 \mathrm{~mm}[15,24]$ and average postoperative LL difference of $1.17 \mathrm{~mm}$ [15]. However, the comparison of LL discrepancies show limitations because of different measuring techniques. In this study a radiological measurement of LL and LL discrepancy was used, while other studies use clinical measurement. Innmann et al. [40] compared reconstruction of individual hip anatomy in patients with a native contralateral hip. An average postoperative LL discrepancy of $-3 \mathrm{~mm}$ could be found in the group with Fitmore short stem. 
Implant positioning showed no statistically significant difference for anteversion, inclination and stem alignment. Studies suggest the risk of varus malpositioning of femoral straight shafts in DAA [41]. The findings in this study shows no difference in stem alignment with Fitmore short stem for DAA and AL MIS approach, but shows a tendency of a varus implantation with an average varus degree of $5.33^{\circ}$ for DAA and $5.46^{\circ}$ for AL MIS approach. This could be a result of the generally calcar guided implantation technique of this stem system. MIS approaches (anterolateral, twoincision, lateral and posterior) were described as a risk factor for cup malpositioning in large patient series [8, 9]. Innmann et al. [7] found a statistically significant malpositioning of acetabular components in minimally invasive anterolateral approach according to Röttinger [4] compared with transgluteal approach. A positioning within the target zone was demonstrated in $89 \%$ for inclination and $71 \%$ for anteversion in minimally invasive anterolateral approach. The findings in this study show similar results for inclination within the target zone of $92.9 \%$ in DAA and $83 \%$ in minimally invasive supine anterolateral approach. Regarding anteversion this study suggests a lower number of cups within the target zone with only $57.1 \%$ and $53.2 \%$ for DAA and AL MIS. Soderquist et al. [42] described a comparable rate of $85 \%$ within the same target zone for inclination and $61 \%$ for anteversion in freehand placement of acetabular cup in DAA. Rathod et al. [43] reported a higher number of cups within the target zone for DAA with fluoroscopy. However, DAA with fluoroscopy was compared to posterior approach without fluoroscopy. Bingham et al. [44] compared cup placement in DAA with and without fluoroscopy and did not find any significant difference in cup positioning and leg length difference. We postulate, that the risk for cup malpositioning is comparable in DAA and MIS anterolateral approach, because of the reduced surgical exposure in both approaches.

Regarding metaphyseal/diaphyseal filling the canal fill index was evaluated in this study. Innmann et al. [40] found an average CFI of $85.6 \%$, CFII of $90.4 \%$ and CFIII of $85.2 \%$ for Fitmore short stem in a modified lateral approach according to Bauer and Russe [45]. The findings in this study show slightly lower canal fill indicis for both approaches. Both minimally invasive approaches show slightly lower results with an average CFI of $79.8 \%$ and $80.25 \%$, an average CFII of $82.7 \%$ and $83.07 \%$ an average CFIII of $85.85 \%$ in DAA and $83.81 \%$ AL MIS approach. These findings for minimally invasive approaches was also found in comparable studies with canal fill indices ranging from 77 to $94 \%$ in DAA with Fitmore short stem [46]. These lower canal fill indices could be a result of slightly impaired femoral broaching due to reduced femoral exposure in minimally invasive approaches.

Limitations of this study are the retrospective study design and the low case number. The retrospective design could lead to a selection bias because of missing prospective randomization. An additional limitation is the evaluation on plain two-dimensional digital radiographs. These can result in a bias because of poor quality of X-ray, e.g., in missing landmarks. This was address with exclusion of patients with insufficient X-rays for radiographic evaluation of the chosen parameters. The use of standardized radiographic techniques and previously described and used measurement techniques for evaluating offset and implant parameters. The strengths of this study first result of being a single-surgeon experience. Second, the measurements are easily reproducible and comparable to existing data.

\section{Conclusion}

Fitmore curved short stem shows an equal reconstruction of femoro-acetabular offset, leg length and implant positioning in direct anterior approach and minimally invasive supine anterolateral approach. The results of this study show comparable results with Fitmore stem to the existing literature regarding offset reconstruction and restoration of leg length. Malposition of the acetabular component regarding anteversion poses a risk and surgeons should be aware when using minimally invasive approaches. Regarding reconstruction of femoro-acetabular offset, leg length and implant positioning direct anterior and minimally invasive supine anterolateral approach show sufficient results.

Acknowledgements Corresponding author M.L. and last author B.S contributed work equally to this study.

Funding Open access funding provided by Johannes Kepler University Linz. This study was carried out as an academic study without any funding.

\section{Declarations}

Conflict of interest We report personal fees paid to our institution during the conduct of the study from Zimmer Biomet, Europe and from Depuy Synthes Orthopädie Gmbh, Peter Brehm Gmbh outside the submitted work. We report research grants paid to our institution during the conduct of the study from Zimmer Biomet, Europe, Depuy Synthes Orthopädie Gmbh, Peter Brehm Gmbh, Germany, outside the submitted work. Two Co-Authors (Rainer Hochgatterer, MD, Günter Hipmair, MD, disclose an activity as paid consultants for Zimmer Biomet outside the submitted work.

Ethical approval The study was approved by the local ethics committee (EK-No.: 1239/2019). All procedures performed in studies involving human participants were in accordance with the ethical standards of the institutional and/or national research committee and with the 1964 Helsinki declaration and its later amendments or comparable ethical standards.

Open Access This article is licensed under a Creative Commons Attribution 4.0 International License, which permits use, sharing, adaptation, distribution and reproduction in any medium or format, as long as you give appropriate credit to the original author(s) and the source, 
provide a link to the Creative Commons licence, and indicate if changes were made. The images or other third party material in this article are included in the article's Creative Commons licence, unless indicated otherwise in a credit line to the material. If material is not included in the article's Creative Commons licence and your intended use is not permitted by statutory regulation or exceeds the permitted use, you will need to obtain permission directly from the copyright holder. To view a copy of this licence, visit http://creativecommons.org/licenses/by/4.0/.

\section{References}

1. Reichert JC, von Rottkay E, Roth F, Renz T, Hausmann J, Kranz J, Rackwitz L, Noth U, Rudert M (2018) A prospective randomized comparison of the minimally invasive direct anterior and the transgluteal approach for primary total hip arthroplasty. BMC Musculoskelet Disord 19(1):241. https://doi.org/10.1186/ s12891-018-2133-4

2. Antoniadis A, Dimitriou D, Flury A, Wiedmer G, Hasler J, Helmy N (2018) Is direct anterior approach a credible option for severely obese patients undergoing total hip arthroplasty? A matched-control, retrospective. Clin Stud J Arthroplast 33(8):2535-2540. https://doi.org/10.1016/j.arth.2018.03.071

3. Chimento GF, Pavone V, Sharrock N, Kahn B, Cahill J, Sculco TP (2005) Minimally invasive total hip arthroplasty: a prospective randomized study. J Arthroplasty 20(2):139-144. https:// doi.org/10.1016/j.arth.2004.09.061

4. Bertin KC, Rottinger H (2004) Anterolateral mini-incision hip replacement surgery: a modified Watson-Jones approach. Clin Orthop Relat Res 429:248-255

5. Barrett WP, Turner SE, Leopold JP (2013) Prospective randomized study of direct anterior vs postero-lateral approach for total hip arthroplasty. J Arthroplasty 28(9):1634-1638. https:// doi.org/10.1016/j.arth.2013.01.034

6. Lovell TP (2008) Single-incision direct anterior approach for total hip arthroplasty using a standard operating table. J Arthroplasty 23(7 Suppl):64-68. https://doi.org/10.1016/j.arth.2008. 06.027

7. Innmann MM, Streit MR, Kolb J, Heiland J, Parsch D, Aldinger PR, Konigshausen M, Gotterbarm T, Merle C (2015) Influence of surgical approach on component positioning in primary total hip arthroplasty. BMC Musculoskelet Disord 16:180. https://doi.org/ 10.1186/s12891-015-0623-1

8. Callanan MC, Jarrett B, Bragdon CR, Zurakowski D, Rubash HE, Freiberg AA, Malchau H (2011) The John Charnley Award: risk factors for cup malpositioning: quality improvement through a joint registry at a tertiary hospital. Clin Orthop Relat Res 469(2):319-329. https://doi.org/10.1007/s11999-010-1487-1

9. Hailer NP, Weiss RJ, Stark A, Karrholm J (2012) The risk of revision due to dislocation after total hip arthroplasty depends on surgical approach, femoral head size, sex, and primary diagnosis. An analysis of 78,098 operations in the Swedish Hip arthroplasty register. Acta Orthop 83(5):442-448. https://doi.org/10.3109/ 17453674.2012.733919

10. Gkagkalis G, Goetti P, Mai S, Meinecke I, Helmy N, Bosson D, Kutzner KP (2019) Cementless short-stem total hip arthroplasty in the elderly patient-is it a safe option?: a prospective multicentre observational study. BMC Geriatr 19(1):112. https://doi.org/10. 1186/s12877-019-1123-1

11. Cinotti G, Della Rocca A, Sessa P, Ripani FR, Giannicola G (2013) Thigh pain, subsidence and survival using a short cementless femoral stem with pure metaphyseal fixation at minimum 9-year follow-up. Orthop Traumatol Surg Res 99(1):30-36. https://doi.org/10.1016/j.otsr.2012.09.016
12. Synder M, Krajewski K, Sibinski M, Drobniewski M (2015) Periprosthetic bone remodeling around short stem. Orthopedics 38(3 Suppl):S40-45. https://doi.org/10.3928/01477447-20150 215-55

13. Pisecky L, Hipmair G, Schauer B, Bohler N (2018) 30-years of experience with the cementless implanted Alloclassic total hip arthroplasty system - an ultra-long-term follow-up. J Orthop 15(1):18-23. https://doi.org/10.1016/j.jor.2017.11.003

14. Snijders TE, van Erp JHJ, de Gast A (2019) Restoring femoral offset and leg length; the potential of a short curved stem in total hip arthroplasty. J Orthop 16(5):396-399. https://doi.org/10.1016/j. jor.2019.04.013

15. Kutzner KP, Kovacevic MP, Roeder C, Rehbein P, Pfeil J (2015) Reconstruction of femoro-acetabular offsets using a shortstem. Int Orthop 39(7):1269-1275. https://doi.org/10.1007/ s00264-014-2632-3

16. Delp SL, Wixson RL, Komattu AV, Kocmond JH (1996) How superior placement of the joint center in hip arthroplasty affects the abductor muscles. Clin Orthop Relat Res 328:137-146. https:// doi.org/10.1097/00003086-199607000-00022

17. Little NJ, Busch CA, Gallagher JA, Rorabeck CH, Bourne RB (2009) Acetabular polyethylene wear and acetabular inclination and femoral offset. Clin Orthop Relat Res 467(11):2895-2900. https://doi.org/10.1007/s11999-009-0845-3

18. Lenaerts G, De Groote F, Demeulenaere B, Mulier M, Van der Perre G, Spaepen A, Jonkers I (2008) Subject-specific hip geometry affects predicted hip joint contact forces during gait. J Biomech 41(6):1243-1252. https://doi.org/10.1016/j.jbiomech.2008. 01.014

19. McGrory BJ, Morrey BF, Cahalan TD, An KN, Cabanela ME (1995) Effect of femoral offset on range of motion and abductor muscle strength after total hip arthroplasty. J Bone Joint Surg Br 77(6):865-869

20. Sakalkale DP, Sharkey PF, Eng K, Hozack WJ, Rothman RH (2001) Effect of femoral component offset on polyethylene wear in total hip arthroplasty. Clin Orthop Relat Res 388:125-134. https:// doi.org/10.1097/00003086-200107000-00019

21. Asayama I, Chamnongkich S, Simpson KJ, Kinsey TL, Mahoney OM (2005) Reconstructed hip joint position and abductor muscle strength after total hip arthroplasty. J Arthroplasty 20(4):414-420. https://doi.org/10.1016/j.arth.2004.01.016

22. Cassidy KA, Noticewala MS, Macaulay W, Lee JH, Geller JA (2012) Effect of femoral offset on pain and function after total hip arthroplasty. J Arthroplasty 27(10):1863-1869. https://doi.org/10. 1016/j.arth.2012.05.001

23. Pakpianpairoj C (2012) Perception of leg length discrepancy after total hip replacement and its impact on quality of life. J Med Assoc Thai 95(Suppl 10):S105-108

24. Erivan R, Muller AS, Villatte G, Millerioux S, Mulliez A, Boisgard S, Descamps S (2020) Short stems reproduce femoral offset better than standard stems in total hip arthroplasty: a casecontrol study. Int Orthop 44(1):45-51. https://doi.org/10.1007/ s00264-019-04355-5

25. Hohle P, Schroder SM, Pfeil J (2015) Comparison between preoperative digital planning and postoperative outcomes in 197 hip endoprosthesis cases using short stem prostheses. Clin Biomech (Bristol, Avon) 30(1):46-52. https://doi.org/10.1016/j.clinb iomech.2014.11.005

26. Unnanuntana A, Wagner D, Goodman SB (2009) The accuracy of preoperative templating in cementless total hip arthroplasty. J Arthroplasty 24(2):180-186. https://doi.org/10.1016/j.arth.2007. 10.032

27. Slotkin EM, Patel PD, Suarez JC (2015) Accuracy of fluoroscopic guided acetabular component positioning during direct anterior total hip arthroplasty. J Arthroplasty 30(9 Suppl):102-106. https:// doi.org/10.1016/j.arth.2015.03.046 
28. Rachbauer F (2005) Minimally invasive total hip arthroplasty via direct anterior approach. Orthopade 34(11):1103-1104. https:// doi.org/10.1007/s00132-005-0854-1 (1106-1108, 1110)

29. Berend KR, Mirza AJ, Morris MJ, Lombardi AV Jr (2016) Risk of periprosthetic fractures with direct anterior primary total hip arthroplasty. J Arthroplasty 31(10):2295-2298. https://doi.org/10. 1016/j.arth.2016.03.007

30. Pfeil J (2010) Minimally invasive surgery in total hip arthroplasty. Springer, Berlin

31. Gustke K (2012) Short stems for total hip arthroplasty: initial experience with the Fitmore stem. J Bone Joint Surg Br 94(11 Suppl A):47-51. https://doi.org/10.1302/0301-620X.94B11. 30677

32. Lewinnek GE, Lewis JL, Tarr R, Compere CL, Zimmerman JR (1978) Dislocations after total hip-replacement arthroplasties. J Bone Joint Surg Am 60(2):217-220

33. Dastane M, Dorr LD, Tarwala R, Wan Z (2011) Hip offset in total hip arthroplasty: quantitative measurement with navigation. Clin Orthop Relat Res 469(2):429-436. https://doi.org/10.1007/ s11999-010-1554-7

34. Wedemeyer C, Quitmann H, Xu J, Heep H, von Knoch M, Saxler G (2008) Digital templating in total hip arthroplasty with the Mayo stem. Arch Orthop Trauma Surg 128(10):1023-1029. https://doi.org/10.1007/s00402-007-0494-5

35. Merle C, Waldstein W, Pegg E, Streit MR, Gotterbarm T, Aldinger PR, Murray DW, Gill HS (2012) Femoral offset is underestimated on anteroposterior radiographs of the pelvis but accurately assessed on anteroposterior radiographs of the hip. J Bone Joint Surg Br 94(4):477-482. https://doi.org/10.1302/0301-620X.94B4. 28067

36. Aldinger PR, Jung AW, Breusch SJ, Ewerbeck V, Parsch D (2009) Survival of the cementless Spotorno stem in the second decade. Clin Orthop Relat Res 467(9):2297-2304. https://doi.org/10.1007/ s11999-009-0906-7

37. Lu M, Zhou YX, Du H, Zhang J, Liu J (2013) Reliability and validity of measuring acetabular component orientation by plain anteroposterior radiographs. Clin Orthop Relat Res 471(9):29872994. https://doi.org/10.1007/s11999-013-3021-8

38. Dorr LD, Faugere MC, Mackel AM, Gruen TA, Bognar B, Malluche HH (1993) Structural and cellular assessment of bone quality of proximal femur. Bone 14(3):231-242. https://doi.org/10. 1016/8756-3282(93)90146-2

39. Laine HJ, Pajamaki KJ, Moilanen T, Lehto MU (2001) The femoral canal fill of two different cementless stem designs. The accuracy of radiographs compared to computed tomographic scanning. Int Orthop 25(4):209-213. https://doi.org/10.1007/ s002640100245

40. Innmann MM, Spier K, Streit MR, Aldinger PR, Bruckner T, Gotterbarm T, Merle C (2018) Comparative analysis of the reconstruction of individual hip anatomy using 3 different cementless stem designs in patients with primary hip osteoarthritis. J Arthroplasty 33(4):1126-1132. https://doi.org/10.1016/j.arth.2017.11. 026

41. Haversath M, Lichetzki M, Serong S, Busch A, Landgraeber S, Jager M, Tassemeier T (2020) The direct anterior approach provokes varus stem alignment when using a collarless straight tapered stem. Arch Orthop Trauma Surg. https://doi.org/10.1007/ s00402-020-03457-9

42. Soderquist MC, Scully R, Unger AS (2017) Acetabular placement accuracy with the direct anterior approach freehand technique. J Arthroplasty 32(9):2748-2754. https://doi.org/10.1016/j.arth. 2017.04.011

43. Rathod PA, Bhalla S, Deshmukh AJ, Rodriguez JA (2014) Does fluoroscopy with anterior hip arthroplasty decrease acetabular cup variability compared with a nonguided posterior approach? Clin Orthop Relat Res 472(6):1877-1885. https://doi.org/10.1007/ s11999-014-3512-2

44. Bingham JS, Spangehl MJ, Hines JT, Taunton MJ, Schwartz AJ (2018) Does intraoperative fluoroscopy improve limb-length discrepancy and acetabular component positioning during direct anterior total hip arthroplasty? J Arthroplasty 33(9):2927-2931. https://doi.org/10.1016/j.arth.2018.05.004

45. Bauer R, Russe W (1984) The transgluteal approach in hip joint arthroplasty. Z Orthop Ihre Grenzgeb 122(1):48-49. https://doi. org/10.1055/s-2008-1044583

46. Rivera F, Leonardi F, Evangelista A, Pierannunzii L (2016) Risk of stem undersizing with direct anterior approach for total hip arthroplasty. Hip Int 26(3):249-253. https://doi.org/10.5301/hipint.5000337

Publisher's Note Springer Nature remains neutral with regard to jurisdictional claims in published maps and institutional affiliations. 